\section{More the people than the place}

Dr R. S. Bray, Director of the Medical Research Council laboratories in The Gambia, looks at life and work there.

THE 1975 balance sheet for medical research in The Gambia shows a reasonably healthy credit. Not everyone wants to do their medical research in a tiny republic stuck out in the savannah of West Africa, but there are compensations. The research is directly about people: organisms and medical phenomena are in people not guinea pigs, and epidemiology figures large. For this you need not merely people, you need nice friendly people. and an understanding population helps to make this the Kingdom of Heaven to an epidemiologist.

The Gambia's people have a willing belief in the delights and benefits of medical research and a considerable dignity to abash the over-assertive. When it came to importing a South African worker to do some haematological investigations, it was with some misgivings that the Ministry of Health was approached about his entry. But"Bring him in," they said, "we'll show him how nice we are". And they did: he came back the following year and is now thinking of teaching them Rugby!

There are some drawbacks, of course. The rainy season can be tiresome, though there's lots of lovely organisms rife. Distinct seasons do make epidemiology interesting, but it's hard to work full-time on parasites which insist on disappearing by February and not reappearing until July. And of course we are remote. The cut and thrust of one's peers is sorely missed-each researcher tends to be working on a sufficiently different subject to be able to make confident statements based on shaky premises with never a demur heard.

Efforts continue to be made to get onto good terms with The Gambia's neighbours. Visits to Dakar are regular for such essentials as liquid nitrogen and frog's legs. But efforts to revive some institutional form of anglophone West African co-operation in medical research move slowly. The giant to the south-Nigeria-looms over all calculations. They have their own organisations, and the knowledge that they will foot the larger part of the bill for regional co-operative efforts doesn't impel them precipitously into such endeavours. But some concrete results have emerged. A collaborative investigation on malaria and the oral contraceptive pill was initiated between the
Komfo Anokye Hospital, Kumasi, Ghana and the MRC, Gambia with IPPF acting as midwife. Equipment has been another productive source of co-operation. It isn't worth $£ 15,000$ (for a cobalt 60 source) to irradiate some malaria infected mosquitoes occasionally, so they are taken to Accra where the Ghana Atomic Energy Commission's machine is used with their enthusiastic co-operation.

Malaria figures large as always in medical research. It is still uncontrolled in Africa though the easy availability of antimalarial drugs and domestic sprays is having an effect in and around cities. The sexual forms of the malaria parasite are being studied to see how and when it arises. The major gaps in the knowledge of African malaria are the reasons for the slow and gradual acquisition of immunity, but techniques for exploration of this phenomenon are hard to come by. Work is going on to investigate malaria in the first six months of life and in pregnant women, where variations in immune status may offer some clues. Vaccination is on the horizon, and work continues on the techniques necessary for the collection of suitable antigen. Work is also done on filariasis and the onset of elephantiasis, schistosomiasis and the longevity of the worm in the face of acquired immunity, the effect of various diseases on cellular immune processes, malnutrition and the contribution of disease to the onset of marasmus, the manner in which female mosquitoes find their hosts, the contribution of mycotoxins to primary hepatoma and on the susceptibility of N'Dama cattle to trypanosomiasis.

And of course there is the grandest tropical health study of them all--Ian McGregor's 26-year-old survey of 4 rural communities in West Kiang district. This unique work brings together 26 years of morbidity and mortality data, growth statistics, endemic and epidemic disease information, serological results and medical genetics. When eventually collected and collated it will form a standard of reference for medical demography and for medical genetics unsurpassed in Africa. Already the information spun off has been of enormous importance.

Always looming, however, is the fact that 4 to 5 of every 10 children born in Black Africa die before adolescence. When projects are designed, this fact can encourage, even justify-for if an experiment works which brings the disappearance of this disease forward one month, 100,000 lives might be saved. A sobering thought.

\section{IN BRIEF}

\section{JET lag}

EEC efforts to take the Joint European Torus (JET) fusion reactor from the design to the construction and experimental stage were still stuck firmly in the political mud last week when community ministers failed to agree on a site for the project after a 16-hour tussle in Brussels. There was agreement on building and financing the project, but national opposition to an earlier Commission finding in favour of the site at the community's joint research centre at Ispra, northern Italy, forced an impasse which the ministers finally sought to resolve by establishing a new committee; this will investigate the relative technical advantages of the contending sites and decide whether experience in fusion research and plasma physics is relevant in choosing between them. Ministers are due to meet again in mid-June, over six months after the next five-year stage of the $£ 96$-million EEC fusion research programme should have begun.

\section{Nuclear trade measures}

In Washington, a Senate sub-committee on arms control heard last week that the "Group of Seven" nuclear exporting nations-Britain, Canada, France, Japan, the Soviet Union, the United States, and West Germany-have agreed still-secret measures to extend safeguards against the misuse of exported nuclear technology. Some clue to the nature of the pact comes from new US Government principles which require foreign recipients of nuclear facilities, equipment and materials to comply with the internationally accepted safeguards already laid down by the International Atomic Energy Agency (IAEA), and to demand identical assurances from any country subsequently handed similar technology. Recipients will also be restricted from using imported facilities for explosive purposes, whether peaceful or not, as a result of the new US policy.

\section{Serendipity in science?}

"There is nothing more practical than a good theory", said Mr Brezhnev, addressing the Twenty-Fifth Congress of the Communist Party of the Soviet Union last week. These words, reiterated by Academician Anatolii P. Aleksandrov, President of the Soviet Academy of Sciences, were apparently intended to justify expenditure on basic research in a Five Year Plan which urges that science should be made costeffective and more closely linked to production. Citing examples ranging from nuclear physics and MHDgenerators to cytology and genetics, 